\title{
PDX-1 and Msx-2 expression in the regenerating and developing pancreas
}

\author{
M R Kritzik' ${ }^{1}$ E Jones ${ }^{1}$, Z Chen ${ }^{2}$, M Krakowski ${ }^{1}$, T Krahl $^{1}$, \\ A Good ${ }^{1}$, C Wright ${ }^{3}$, H Fox ${ }^{2}$ and N Sarvetnick ${ }^{1}$ \\ ${ }^{1}$ Department of Immunology, The Scripps Research Institute, 10550 North Torrey Pines Road, La Jolla, California 92037, USA \\ ${ }^{2}$ Department of Neuropharmacology, The Scripps Research Institute, La Jolla, California 92037, USA \\ ${ }^{3}$ Vanderbilt University Medical School, Nashville, Tennessee 37232, USA \\ (Requests for offprints should be addressed to N Sarvetnick; Email: noras@scripps.edu) \\ (E Jones is now at School of Medicine, Department of Physiology, University of Maryland, Baltimore, Maryland 21201, USA)
}

\begin{abstract}
We have observed pancreatic duct cell proliferation and islet regeneration in transgenic mice whose pancreata produce interferon $\gamma$ (IFNg mice). We have previously demonstrated that new islet cells derive from endocrine progenitor cells in the pancreatic ducts of this model. The current study was initiated to define these endocrine progenitor cells further and to identify novel markers associated with pancreatic regeneration. Importantly, we have found that PDX-1, a transcription factor required for insulin gene transcription as well as for pancreatic development during embryogenesis, is expressed in the duct cells of IFNg mice. This striking observation suggests an important role for PDX-1 in the marked regeneration
\end{abstract}

observed in IFNg mice, paralleling its critical function during ontogeny. Also demonstrated was elevated expression of the homeobox-containing protein Msx-2 in the pancreata of fetal mice as well as in adult IFNg mice, identifying this molecule as a novel marker associated with pancreatic development and regeneration as well. The identification of PDX-1 and Msx in the ducts of the IFNg transgenic pancreas but not in the ducts of the nontransgenic pancreas suggests that these molecules are associated with endocrine precursor cells in the ducts of the IFNg transgenic mouse.

Journal of Endocrinology (1999) 163, 523-530

\section{Introduction}

Insulin-dependent, or type I, diabetes mellitus is characterized by the selective destruction of the insulinsynthesizing and insulin-secreting beta cells of the pancreatic islets of Langerhans, rendering type I diabetic patients dependent on exogenous insulin for life. Therefore, experimental models of pancreatic regeneration are vital for developing any treatment strategy aimed at alleviating the consequences of this disease. This rationale propels our continuing studies of the interferon- $\gamma$ producing (IFNg) transgenic mouse. These mice, which express IFNg in the beta cells of their pancreatic islets, undergo ductal hyperplasia and destruction of islets by infiltrating lymphocytes (Sarvetnick et al. 1988, Gu \& Sarvetnick 1993). Remarkably, though, such mice undergo considerable islet regeneration. The newly formed islets bud into the lumen of ducts. The aggressive growth of pancreatic ducts and the continuous differentiation of new endocrine cells during adult life indicate that islet stem cells responsible for this extraordinary regrowth occupy the transgenic animals' pancreata. Here, we attempted to define the stem cells responsible for this pancreatic regrowth, as well as to identify markers associated with the regenerative process.

Elegant and important experiments recently demonstrated that transcription factors important for insulin gene expression are critical for the development of the pancreas during embryogenesis (see Sander \& German 1997 for review). PDX-1 (also called IDX-1, IPF-1, or STF-1), a transcription factor that regulates insulin expression, is one important marker (reviewed in Peshavaria \& Stein 1997). PDX-1 is expressed in the pancreatic islets of adult mice but is absent from duct cells and acinar tissue (Ohlsson et al. 1993). The fact that PDX-1-deficient mice lack a pancreas and die shortly after birth indicates the absolute requirement for PDX-1 during pancreatic development (Jonsson et al. 1994, Offield et al. 1996). Additionally, PDX-1 functions in determination and/or maintenance of the pancreatic identity of common precursor cells (Peshavaria \& Stein 1997).

Like PDX-1, Msx-2 is a homeobox-containing transcription factor. Msx-2 is part of a conserved family of transcription factors that play critical roles in tissue 
patterning and organogenesis during development (Davidson \& Hill 1991, Davidson 1995). For example, the involvement of Msx-2 in bone and tooth development has been well described (Ignelzi et al. 1995, Maas \& Bei 1997). Notably, Msx-2 is expressed at a wide variety of sites in the developing embryo, suggesting its involvement in the generation of a number of organ systems (Davidson \& Hill 1991, Davidson 1995). Nevertheless, no specific role for Msx-2 in pancreatic development is known.

PDX-1 and Msx expression patterns were studied to define and characterize further the progenitor cells that give rise to islet cells in the IFNg transgenic model of pancreatic regeneration. Whereas Msx-2 was selected for study after it was found to be dramatically elevated in the IFNg regenerating pancreas in a differential cDNA analysis (described below), PDX-1 was selected for study based on its critical and proven role in pancreatic development. Indeed, Sharma et al. (1999) recently published a report demonstrating the induction of PDX-1 in rat ducts following partial pancreatectomy. These authors further suggested that PDX-1 might be involved in the derivation of beta cells from ductal cells. Importantly, we now report significant expression of PDX-1 and Msx proteins in the ducts of the IFNg transgenic pancreas.

\section{Materials and Methods}

\section{Animal husbandry}

Animals were maintained in a specific pathogen-free facility at The Scripps Research Institute according to the rules and regulations governed and enforced by the Institutional Animal Care and Use Committee. Animals were housed under a controlled 12-h light/darkness cycle with food and water available ad libitum. The embryos used in these studies did not carry the IFNg transgene.

\section{Transgenic mouse generation}

Transgenic mice expressing IFNg have been described previously (Sarvetnick et al. 1988). The IFNg transgenic mice used in these studies were on the non-obese diabetic (NOD) background. IFNg mice that have been backcrossed onto the NOD/Shi strain for more than ten generations have a very low incidence of diabetes, $<20 \%$, compared with NOD mice which have an incidence of $\sim 80 \%$ for females and $\sim 25 \%$ for males.

\section{Immunohistochemistry}

Pancreata from test mice were fixed overnight in $10 \%$ neutral buffered formalin (3.6\% formaldehyde) and embedded in paraffin. Paraffin sections $(5 \mu \mathrm{m})$ were either conventionally stained with hematoxylin and eosin for histological evaluation or stained for the presence of insulin, PDX-1, or Msx using immunocytochemical techniques. Briefly, sections were deparaffinized and blocked with $2 \%$ normal goat serum before applying the primary antibodies for insulin (DAKO, Carpentaria, CA, USA), Msx (BAbCO, Richmond, CA, USA), or PDX-1 (a generous gift from Dr Chris Wright, Vanderbilt University Medical School, Nashville, TN, USA and Dr Helena Edlund, University of Umeå, Umeå, Sweden). Binding of the primary antibody was detected using the appropriate secondary antibody (Vector Laboratories, Burlingame, CA, USA), and the horseradish peroxidase (HRP)-labeled avidin-biotin complex (ABC kit, Vector Laboratories). HRP was visualized using 3,3'diaminobenzidine as a substrate. Gill's hematoxylin was used as a counterstain.

\section{Immunoelectron microscopy}

Pancreatic tissue was fixed in 10\% normal buffered formalin $\left(3 \cdot 6 \%\right.$ formaldehyde) for $2 \mathrm{~h}$ at $25{ }^{\circ} \mathrm{C}$. Fixed tissue was infused in $1.5 \mathrm{M}$ sucrose-PBS for $0.5 \mathrm{~h}$ with gentle inversion periodically. Infused tissue was then quick-frozen in liquid nitrogen, embedded in OCT and 2 -methylbutane and sectioned $30-40 \mu \mathrm{m}$ thick. These sections were incubated in glycine-PBS to quench aldehyde for $0.5 \mathrm{~h}$, blocked in $10 \%$ normal goat serum for $0.5 \mathrm{~h}$, and incubated for $1 \mathrm{~h}$ each in PDX-1 (primary antibody) and an HRP-conjugated goat anti-rabbit secondary antibody before refixing in 1\% glutaraldehyde-PBS for $0.25 \mathrm{~h}$ and washing in PBS. The reaction product was visualized with diaminobenzidine (DAB) for $7 \mathrm{~min}$ and $\mathrm{DAB}+\mathrm{H}_{2} \mathrm{O}_{2}$ for 4 min before treating with $1 \% \mathrm{OsO}_{4}$. Tissue was dehydrated in graded ethanol, cleared in propylene oxide and embedded in Spurr resin. Thin sections were viewed with a Hitachi HU 12A electron microscope.

\section{Differential gene expression analysis}

The Atlas Mouse cDNA Expression Array I (Clontech, Palo Alto, CA, USA) was used to screen the IFNg NOD-severe combined immunodeficiency (SCID)regenerating pancreas for upregulation of mRNAs relative to the non-transgenic NOD-SCID pancreas. The analysis was carried out according to the manufacturer's recommendations. Msx-2 was one of nineteen transcripts found to be expressed in the regenerating pancreas but not in the non-transgenic pancreas.

\section{Results}

PDX-1 and Msx in the fetal pancreas

We first sought to characterize PDX-1, Msx-2, and insulin expression during fetal pancreatic development for 
Table 1 Summary of PDX-1, Msx, and insulin staining patterns in fetal, IFNg transgenic, and non-transgenic pancreata

\begin{tabular}{|c|c|c|c|}
\hline & PDX-1 & Msx & Insulin \\
\hline \multicolumn{4}{|l|}{ Fetal Balb/c } \\
\hline Duct (cord) & +++ & + & $+/-$ \\
\hline Peri-epithelial & +++ & ++ & ++ \\
\hline Acinar & ++ & $+/-$ & - \\
\hline \multicolumn{4}{|c|}{ Adult IFNg transgenic } \\
\hline Duct & +++ & ++ & + \\
\hline Acinar & - & - & - \\
\hline Islet & +++ & + & +++ \\
\hline \multicolumn{4}{|l|}{ Non-transgenic } \\
\hline Duct & - & - & - \\
\hline Acinar & - & - & - \\
\hline Islet & +++ & + & +++ \\
\hline
\end{tabular}

Plus signs refer to the extent of staining, from low $(+/-)$ to extensive $(+++)$. Peri-epithelial staining refers to staining abutting the ductal cord region.

comparison with that during regeneration, with the results summarized in Table 1. After staining of pancreata from Balb/c embryos at 14.5 days post conception, PDX-1 reactivity was most notable in the cord region of expanding epithelial tissue from which the ducts and endocrine tissue develop, and was also observed in the acinar tissue, consistent with previous reports (Fig. 1A; Ohlsson et al. 1993, Guz et al. 1995). Nuclear staining was clearly observed in the expanding epithelia, as well as in the acinar tissue. Additionally, diffuse non-nuclear staining was apparent within the region of PDX-1 staining. Based upon a number of other studies which clearly demonstrate the nuclear localization of PDX-1, we believe that this nonnuclear staining is probably an artifact due to PDX-1 antigen leakage during fixation of the embryos. Importantly, although less extensive than PDX-1 staining, Msx displayed considerable staining in the expanding epithelia of the developing pancreas where PDX-1 was also detected (Fig. 1B). Both nuclear and diffuse cytoplasmic staining were observed with this antibody as well, and faint nuclear staining in the acinar tissue was also detected (Fig. 1B and Fig. 2A). Finally, insulin-producing cells were also found in the region of expanding epithelia in the embryonic pancreas (Fig. 2B). Compared with PDX-1 and Msx staining, its expression was not as widespread within the cords, but rather was restricted more to the peri-epithelial region (Fig. 2 illustrates this point with a comparison of Msx and insulin staining patterns).

\section{PDX-1 expression in pancreata of IFNg transgenic mice}

To determine if PDX-1 is present in the pancreas during regeneration as well as embryonic development, we screened regenerating pancreata of adult IFNg mice for PDX-1 expression. As shown in Fig. 3A, we found striking expression of PDX-1 in the ducts of the IFNg transgenic mouse. Specifically, we found nuclear localization of PDX-1 in islet cells (as expected), as well as in a proportion of cells within the duct wall. Staining was observed in both small and large ducts, as well as in ducts with and without intraductal islets. Staining of adjacent sections with antibody to insulin revealed that these PDX-1-positive ducts also contained a subpopulation of cells that were positive for insulin (Fig. 3B). PDX-1 expression has not previously been observed in murine pancreatic duct cells (Ohlsson et al. 1993) and, as expected, the ducts from non-transgenic control mice did not express PDX-1 or insulin (Fig. 3C and D). The expression of PDX-1 but not insulin in a subpopulation of ductal cells in IFNg transgenic mice suggests that such cells represent pre-endocrine progenitor cells.

\section{Ultrastructural analysis of PDX-1-expressing duct cells}

We used immunoelectron microscopy to determine the ultrastructure of PDX-1-expressing cells in ducts of the


Figure 1 PDX-1 and Msx immunostaining of the fetal pancreas. Serial sections of an E14.5 embryo were stained with antibody to either PDX-1 (A) or Msx (B). Note the expression of both proteins, albeit at different levels, in the region of epithelial expansion. Original magnification $\times 20$. 

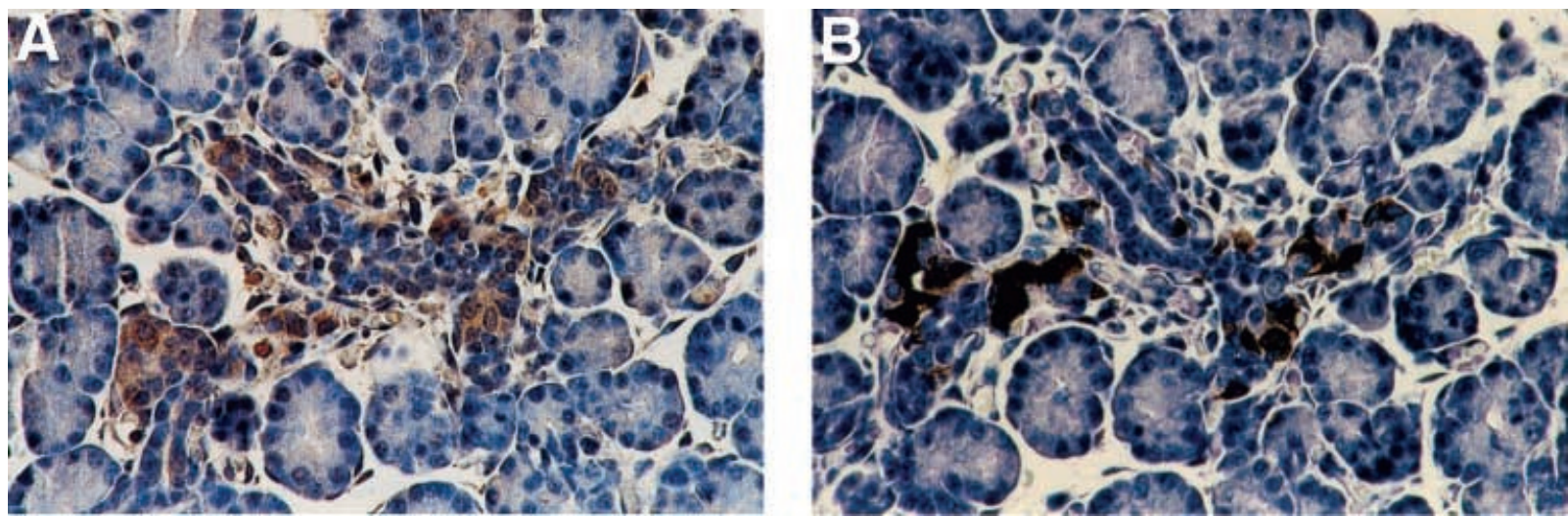

Figure $2 \mathrm{Msx}$ and insulin immunostaining of the fetal pancreas. Serial sections of an E14.5 embryo were stained with antibody to either Msx (A) or insulin (B). Note that Msx is expressed in both the ductal and peri-epithelial regions, while insulin is found mainly in the peri-epithelial region. Original magnification $\times 50$.

IFNg transgenic mouse. Consistent with our observations that not all PDX-1-expressing cells also expressed insulin, we identified cells which expressed PDX-1 but which were devoid of endocrine granules (Fig. 4). Moreover, we found no significant structural differences among duct cells, regardless of PDX-1 expression. In fact, ductal cells in the regenerating pancreas exhibited many of the morphological features characteristic of ductal epithelial cells,
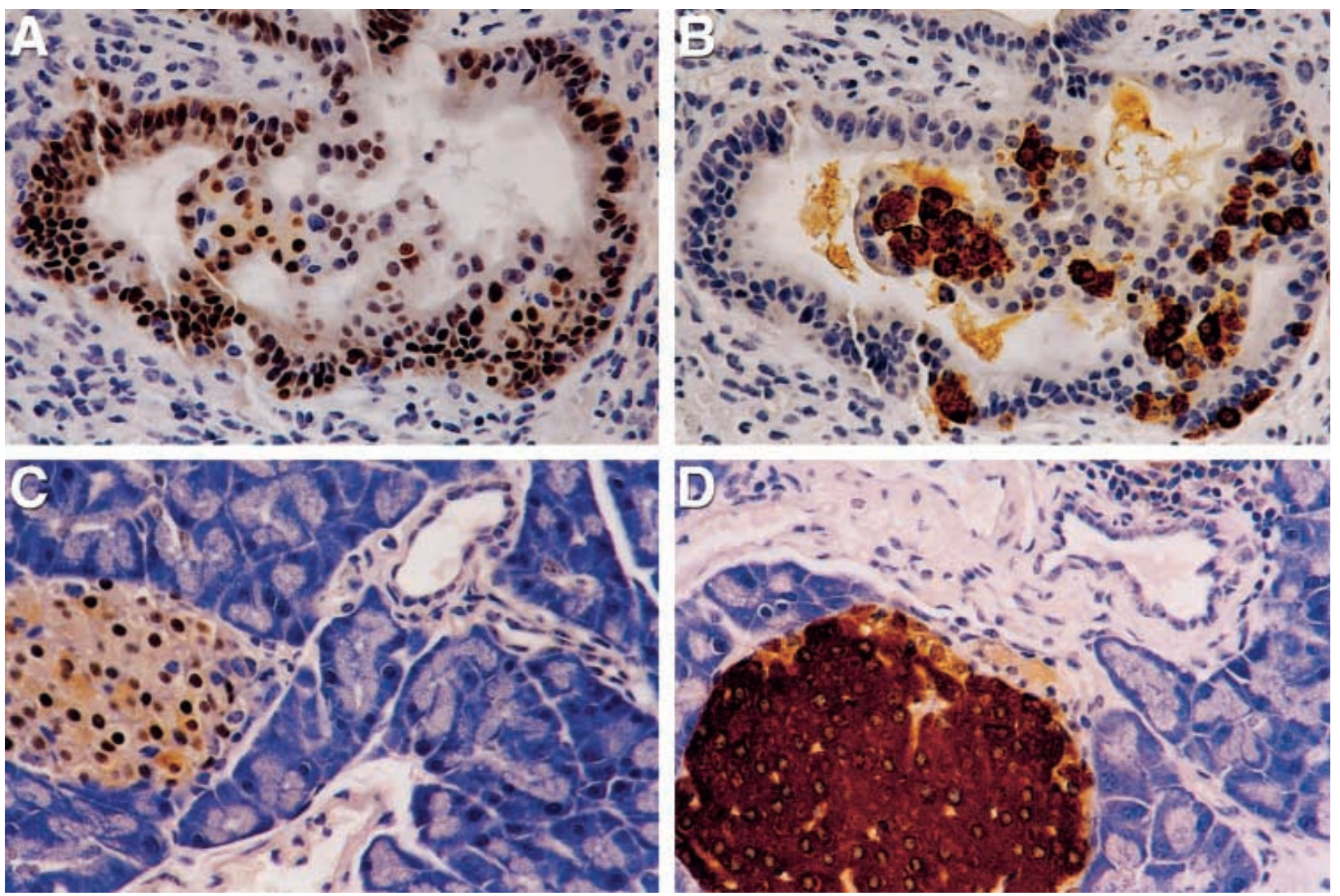

Figure 3 PDX-1 immunostaining in the IFNg transgenic pancreas. Pancreatic sections from an adult IFNg transgenic mouse (A, B) and an adult non-transgenic mouse (C, D) were stained with antibody to either PDX-1 (A, C) or insulin (B, D). Panels A and B are serial sections. Note the presence of both insulin-positive and insulin-negative PDX-1-expressing ductal cells. Original magnification $\times 50$. 


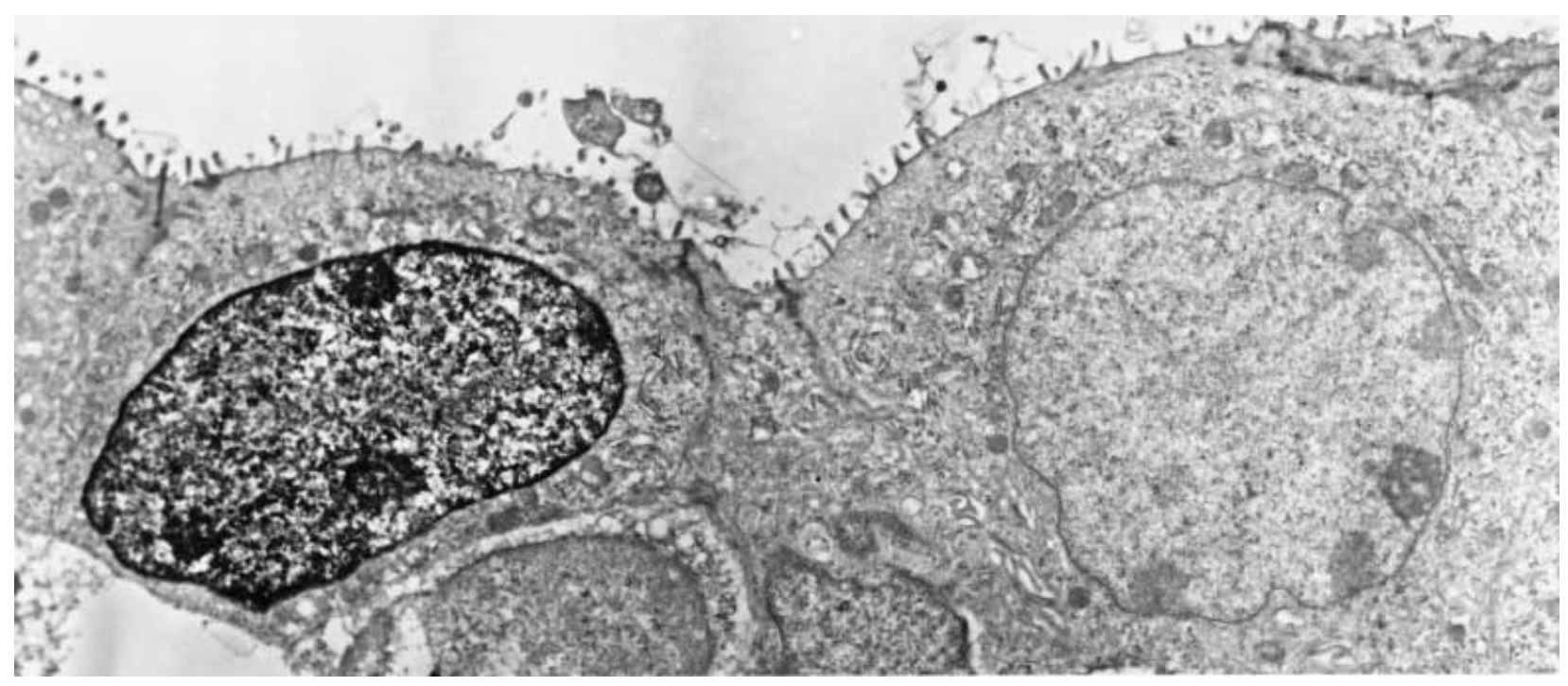

Figure 4 Ultrastructural analysis of PDX-1-expressing ductal cells in the IFNg transgenic pancreas. Immunoelectron microscopy was used to characterize PDX-1-expressing ductal cells in the pancreas of an adult IFNg transgenic mouse. The figure shows a PDX-1-positive cell (left) adjacent to a PDX-1-negative cell (right). Note the similar morphology of these cells. Original magnification $\times 8500$.

including centrally located, irregularly shaped nuclei, numerous interdigitating processes on the lateral aspects of the cells, unspecialized cytoplasm containing mitochondria, sparse elements of rough endoplasmic reticulum, scattered stacks of Golgi lamellae, and a variety of vesicular profiles. The apical plasma membrane possessed typical apical ultrastructural specializations including microvilli and junctional complexes complete with tight junctions (Yamamoto \& Kataoka 1988).

\section{Msx expression in IFNg mice}

We next screened sections of regenerating pancreata from adult IFNg mice for the presence of the Msx proteins by staining with a polyclonal antibody directed against the Msx homeodomain. The only antibody available for this purpose recognizes both the Msx-1 and Msx-2 proteins and probably Msx-3 as well. Our analyses demonstrated diffuse Msx staining throughout the islets of all mice assessed. In contrast, acinar tissue did not stain with the Msx antibody. Importantly, a significant proportion of duct cells in the regenerating pancreas were positive for Msx expression (Fig. 5B and C). We observed staining in the nucleus, as expected for members of this transcription factor family; however, cytoplasmic staining was also observed in many instances. The extent of staining varied among ducts; some ducts had many positive cells and other ducts had few, if any, Msx-positive cells. No Msx expression was evident in the ducts of non-transgenic control mice (data not shown). Furthermore, Msx staining was less extensive than PDX-1 staining in the transgenic ducts, and comparison of serial section staining patterns suggested that Msx-expressing cells also expressed PDX-1 (Fig. 5A and B). Subsequent analyses further suggested coincident staining between insulin and Msx in many instances. Although the similarity in Msx and insulin expression patterns could reflect a basal level of cross-reactivity between the Msx antibodies and endocrine cells (supported by the diffuse islet staining we observe with the Msx antibody), we identified Msx-positive cells that did not stain for insulin in a number of ducts; insulin-positive cells lacking Msx expression were also observed (Fig. 5C and D). Thus, based on PDX-1, Msx, and insulin staining patterns, we suggest that at least four populations of ductal cells, not present in the non-transgenic pancreas, can be identified in the IFNg transgenic pancreas: PDX-1 $1^{+}$ $\mathrm{Msx}^{-}$insulin ${ }^{-}$ductal cells, $\mathrm{PDX}-1^{+} \mathrm{Msx}^{+}$insulin ${ }^{-}$ ductal cells, PDX-1 ${ }^{+} \mathrm{Msx}^{+}$insulin $^{+}$ductal cells, and $\mathrm{PDX}_{-1}{ }^{+} \mathrm{Msx}^{-}$insulin ${ }^{+}$ductal cells.

\section{Discussion}

We have observed the regeneration of islets that bud into the ductal lumen in the IFNg transgenic mouse, where they are protected from destruction by infiltrating lymphocytes. In this study, we used histological analyses to characterize the progenitor cells responsible for the remarkable ductal proliferation and islet regeneration. Indeed, we have now defined markers associated with ducts during regeneration in the IFNg transgenic mouse: PDX-1 and Msx-2. These results suggest that these proteins are associated with endocrine progenitor cells in the ducts of the IFNg transgenic mouse.

The ductal epithelium, which consists of intercalated (small), intralobular (medium) and interlobular (large) 

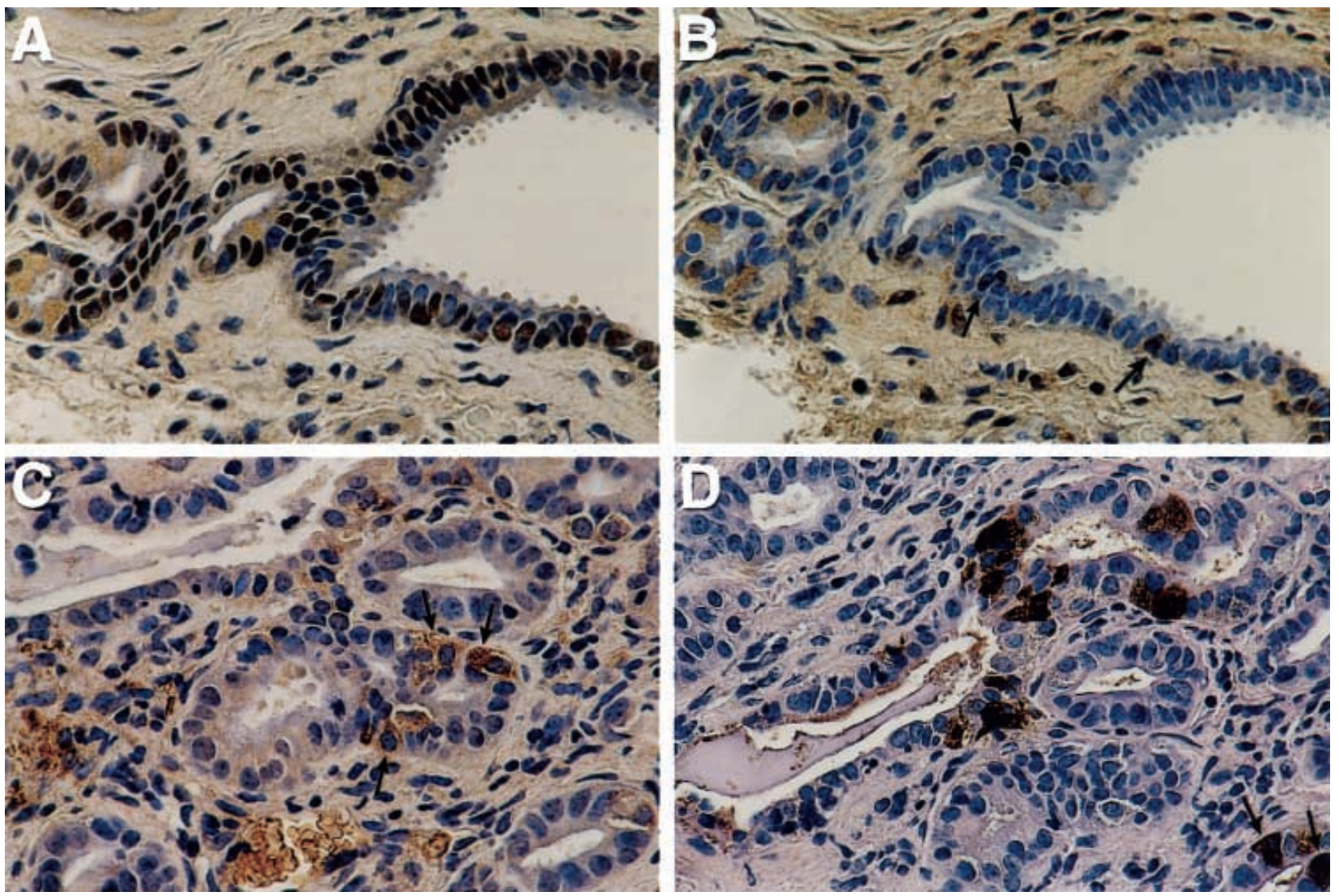

Figure 5 Msx immunostaining in the IFNg transgenic pancreas. Serial sections of the pancreas from an adult IFNg transgenic mouse were stained with antibody to either PDX-1 (A), Msx (B, C), or insulin (D). Note the significant expression of Msx as well as PDX-1 in panels A and $B$ (the arrows in panel B highlight Msx-positive cells in the duct wall). Msx-positive cells lacking insulin expression are indicated by arrows in panel C; insulin-positive cells lacking Msx expression are indicated by arrows in panel D. Panels $C$ and $D$ represent serial sections somewhat offset and at slightly different magnifications. Original magnification A, B, D × 40; $\times 50$.

ducts, has been designated as the site of exocrine and endocrine development in the pancreas (Pictet et al. 1972, Argent et al. 1992, Slack 1995). A specific pathway for islet development in these animals, defined by the expression of duct, exocrine, and endocrine specific antigens, is thought to involve the derivation of endocrine cells from duct cells, which progress through a series of intermediate cell types (Gu et al. 1994). In promoting regeneration and new islet formation, we believe that progenitor stem cells in the ducts of the IFNg transgenic mouse recapitulate the early development of the pancreas. Indeed, parallels exist between normal ontogeny and IFNg-mediated regeneration, and in both cases, endocrine gene expression is an early event. Individual endocrine cells are initially scattered in the duct wall; these cells subsequently migrate to form clusters, which develop into fully differentiated islets. Thus, we hypothesized that endocrine cell precursors would be abundant in the ducts of mice undergoing islet regeneration, as they are in the fetal pancreas.
PDX-1 is thought to be expressed in the earliest pancreatic progenitor cell, from which both exocrine and endocrine cells develop (reviewed in Peshavaria \& Stein 1997). Indeed, whereas PDX-1 is present only in the endocrine cells of the adult, PDX-1-deficient mice have no pancreas at all, indicating the critical role PDX-1 plays in the development of all pancreatic tissue (Jonsson et al. 1994, Offield et al. 1996). Using light and immunoelectron microscopy, we have now found that ductal cells in the transgenic pancreas also express PDX-1. In addition, only a subset of the PDX-1-expressing cells also express insulin. These observations are striking, because they define distinct populations of endocrine precursor cells during pancreatic regeneration and new islet growth. Indeed, we believe that duct cells expressing PDX-1 but not insulin represent early pre-endocrine progenitor cells.

We have also observed substantial expression of PDX-1 in the developing pancreas during ontogeny, as expected given the critical role of this molecule in pancreatic 
development and consistent with reports by others (Ohlsson et al. 1993, Guz et al. 1995). Although its precise functions during ontogeny and regeneration are not clear, the expression of PDX-1 in the IFNg regenerating pancreas appears to recapitulate the requirement for this protein in pancreatic development during ontogeny. Indeed, the ductal derivation of new endocrine cells coupled with PDX-1 expression in the ducts of the IFNg transgenic mouse suggests that the new endocrine cell formation we observe during regeneration in the IFNg transgenic mouse proceeds through mechanisms similar to those active during fetal development.

Recent studies in rats have found weak expression of PDX-1 in the pancreatic ducts of normal rats (Sharma et al. 1999). While PDX-1 expression is not detected in the ducts of normal mice, the expression of PDX-1 in normal rats is weak, and the differences between ductal expression patterns might be attributed to subtle differences between the species. Interestingly, Sharma et al. (1999) have further demonstrated that PDX-1 expression is significantly induced in ductal cells during the regeneration that ensues following partial pancreatectomy. Based on the kinetics of PDX-1 expression, these authors suggested that PDX-1 might be involved in the derivation of new endocrine cells from ductal cells. These studies, therefore, parallel and support our own observations, which suggest a role for PDX-1 in the extensive new endocrine cell formation exhibited by the IFNg transgenic mouse. The ductal expression of PDX-1 in two distinct models of pancreatic regeneration and new islet formation is striking and suggests that PDX-1 serves a central and critical function in the differentiation of endocrine cells, during both ontogeny and regeneration.

Msx-2 is part of a conserved family of homeoboxcontaining transcription factors that regulate tissue growth and patterning during embryogenesis (reviewed in Davidson 1995). Using the Atlas cDNA array to study differential gene expression patterns, we found that Msx-2 is expressed in the regenerating pancreas of the IFNg transgenic mouse. We used immunohistochemistry to confirm these results and to follow expression of the Msx protein directly. These experiments utilized an antibody which detects both Msx-1 and Msx-2, preventing us from drawing conclusions regarding Msx-2 expression specifically from this staining alone. Despite this limitation, we detected significant expression of Msx in the pancreatic ducts of IFNg transgenic mice. This is in contrast to the work of others as well as our own observations in nontransgenic mice demonstrating that the Msx proteins are not expressed in the normal adult mouse pancreas (Maas et al. 1996). Strikingly, we also observed significant expression of Msx in the developing pancreas during embryogenesis. This expression was localized to the growing epithelia from which ducts and endocrine cells arise. Coupled with the fact that we did not observe enhanced Msx-1 expression in the transgenic pancreas using the
Atlas cDNA array, these results support our identification of Msx-2 as a marker associated with endocrine progenitor cells both in the developing and regenerating pancreas. Furthermore, our staining demonstrated considerable cytoplasmic as well as nuclear localization of Msx. As a transcription factor, Msx is expected to be localized in the nucleus, although others have reported its presence as a diffuse cytoplasmic stain as well (Stelnicki et al. 1997). Although this cytoplasmic staining might represent an artifact due to the fixation procedures, it is possible that Msx might be localized to the cytoplasm under certain conditions, as is the case for NFkappaB prior to its activation (Baeuerle \& Baltimore 1988a,b).

A number of studies indicate that Msx-2 can be induced through a signaling network involving members of the transforming growth factor (TGF) beta superfamily, including BMP-4 (Vainio et al. 1993, Marazzi et al. 1997). Although we have not yet explored regulatory aspects of Msx induction in the regenerating pancreas, possibly the cytokine network induced by IFNg in this model contributes directly to the induction of Msx protein. Indeed, previous work in our laboratory has demonstrated significant changes in the cytokine profile of the regenerating pancreas. For example, TGF $\alpha$, interleukin $1 \beta$, and tumor necrosis factor $\alpha$ are elevated in the regenerating pancreas (Arnush et al. 1996 and M Arnush \& N Sarvetnick, unpublished data). At this time, the functional significance of Msx-2 expression in pancreatic regeneration is not clear. Msx-2 is expressed at many sites during development, including the cranial neural crest, neural tube, tooth germs, eyes, ears, nose, limb buds, pituitary, and heart, and, in particular, Msx-2 expression appears to be associated with sites of epithelial-mesenchymal interactions (reviewed in Davidson \& Hill 1991, Davidson 1995). Msx proteins are also thought to be crucial to pattern formation during the development of diverse organs (reviewed in Davidson \& Hill 1991, Davidson 1995). A number of reports have also implicated $\mathrm{Msx}-2$ in the apoptotic program during development (Graham et al. 1993, 1994, Marazzi et al. 1997, Winograd et al. 1997, Ferrari et al. 1998). Although the expression of Msx-2 in the pancreas during development has not been reported previously, the evidence presented here suggests that Msx- 2 might play a critical role in regulating the pancreatic developmental program as well.

The identification of markers associated with endocrine progenitor cells in the IFNg transgenic pancreas is clearly of value, with regards to both defining these precursor cells and in an analysis of the regenerative process. In this study we have correlated the expression of two such molecules, PDX-1 and Msx-2, with the striking pancreatic regeneration exhibited by the IFNg transgenic mouse. Each of these homeodomain proteins appears to play a critical role in organ formation during ontogeny, and each is expressed in the developing as well as the regenerating pancreas. While future studies will be aimed at defining the precise 
contributions of these proteins during pancreatic development and regeneration, their association with pancreatic progenitor cells will be valuable in the isolation and characterization of this critical cell type.

\section{Acknowledgements}

We would like to thank Dr Cheng-ming Chang for his valuable contribution to the electron microscopy studies. We would also like to thank Dr Helena Edlund for her generous gift of PDX-1 antibody, and Phyllis Minick for editorial assistance.

\section{References}

Argent BE, Githens S, Kalser S, Longnecker DS, Metzgar R \& Williams JA 1992 The pancreatic duct cell. Pancreas 7 403-419.

Arnush M, Gu D, Baugh C, Sawyer SP, Mroczkowski B, Krahl T \& Sarvetnick N 1996 Growth factors in the regenerating pancreas of g-interferon transgenic mice. Laboratory Investigation 74 985-990.

Baeuerle PA \& Baltimore D 1988a IkB: a specific inhibitor of the NF-kB transcription factor. Science 242 540-546.

Baeuerle PA \& Baltimore D 1988 b Activation of DNA-binding activity in an apparently cytoplasmic precursor of the NF-kB transcription factor. Cell $\mathbf{5 3}$ 211-217.

Davidson D 1995 The function and evolution of Msx genes: pointers and paradoxes. Trends in Genetics 11 405-411.

Davidson DR \& Hill RE 1991 Msh-like genes: a family of homeobox genes with wide-ranging expression during vertebrate development. Seminars in Developmental Biology 2 405-412.

Ferrari D, Lichter AC, Pan ZZ, Dealy CN, Upholt WB \& Kosher RA 1998 Ectopic expression of Msx-2 in posterior limb bud mesoderm impairs limb morphogenesis while inducing BMP-4 expression, inhibiting cell proliferation, and promoting apoptosis. Developmental Biology 197 12-24.

Graham A, Heyman I \& Lumsden A 1993 Even-numbered rhombomeres control the apoptotic elimination of neural crest cells from odd-numbered rhombomeres in the chick hindbrain. Development 119 233-245.

Graham A, Francis-West P, Brickell P \& Lumsden A 1994 The signalling molecule BMP4 mediated apoptosis in the rhombencephalic neural crest. Nature 372 684-686.

Gu D \& Sarvetnick N 1993 Epithelial cell proliferation and islet neogenesis in IFN-g transgenic mice. Development 118 33-46.

Gu D, Lee MS, Krahl T \& Sarvetnick N 1994 Transitional cells in the regenerating pancreas. Development 120 1873-1881.

Guz Y, Montminy MR, Stein R, Leonard J, Gamer LW, Wright CV \& Teitelman G 1995 Expression of murine STF-1, a putative insulin gene transcription factor, in beta cells of pancreas, duodenal epithelium, and pancreatic exocrine and endocrine progenitors during ontogeny. Development 121 11-18.

Ignelzi Jr MA, Liu Y-H, Maxson Jr RE \& Snead ML 1995 Genetically engineered mice: tools to understand craniofacial development. Critical Reviews in Oral Biology and Medicine 6 181-201.
Jonsson J, Carlsson L, Edlund T \& Edlund H 1994 Insulin-promoter factor 1 is required for pancreas development in mice. Nature 371 606-609.

Maas R \& Bei M 1997 The genetic control of early tooth development. Critical Reviews in Oral Biology and Medicine 8 4-39.

Maas R, Chen YP, Bei M, Woo I \& Satokata I 1996 The role of Msx genes in mammalian development. Annals of the New York Academy of Sciences 785 171-181.

Marazzi G, Wang Y \& Sassoon D 1997 Msx2 is a transcriptional regulator in the BMP4-mediated programmed cell death pathway. Developmental Biology 186 127-138.

Offield MF, Jetton TL, Labosky PA, Ray M, Stein RW, Magnuson MA, Hogan BL \& Wright CV 1996 PDX-1 is required for pancreatic outgrowth and differentiation of the rostral duodenum. Development 122 983-995.

Ohlsson H, Karlsson K \& Edlund T 1993 IPF-1, a homeodomaincontaining transactivator of the insulin gene. EMBO Journal 12 4251-4259.

Peshavaria M \& Stein R 1997 PDX-1: an activator of genes involved in pancreatic development and islet gene expression. In Pancreatic Growth and Regeneration, edn1, pp 96-107. Ed N Sarvetnick. Basel, Switzerland: Karger Landes Systems.

Pictet RL, Clark WR, Williams RH \& Rutter WJ 1972 An ultrastructural analysis of the developing embryonic pancreas. Developmental Biology 29 436-467.

Sander M \& German MS 1997 The $\beta$ cell transcription factors and development of the pancreas. Journal of Molecular Medicine $\mathbf{7 5}$ 327-340.

Sarvetnick N, Liggitt D, Pitts SL, Hansen SE \& Stewart TA 1988 Insulin-dependent diabetes mellitus induced in transgenic mice by ectopic expression of class II MHC and interferon-gamma. Cell $\mathbf{5 2}$ 773-782.

Sharma A, Zangen DH, Reitz P, Taneja M, Lissauer ME, Miller CP, Weir GC, Habener JF \& Bonner-Weir S 1999 The homeodomain protein IDX-1 increases after an early burst of proliferation during pancreatic regeneration. Diabetes 48 507-513.

Slack J 1995 Developmental biology of the pancreas. Development 121 1569-1580.

Stelnicki EJ, Komuves LG, Holmes D, Clavin W, Harrison MR, Adzick NS \& Largman C 1997 The human homeobox genes MSX-1, MSX-2, and MOX-1 are differentially expressed in the dermis and epidermis in fetal and adult skin. Differentiation 62 33-41.

Vainio S, Karavanova I, Jowett A \& Thesleff I 1993 Identification of BMP-4 as a signal mediating secondary induction between epithelial and mesenchymal tissues during early tooth development. Cell 75 45-58.

Winograd J, Reilly MP, Roe R, Lutz J, Laughner E, Xu X, Hu L, Asakura T, vander Koli C, Strandburg JD \& Semenza GL 1997 Perinatal lethality and multiple craniofacial malformations in MSX2 transgenic mice. Human Molecular Genetics 6 369-379.

Yamamoto M \& Kataoka K 1988 An electron microscope study of the development of the exocrine and endocrine pancreas with special reference to intercellular junctions. Archives of Histology and Cytology 51 315-325.

Received 14 April 1999

Accepted 13 July 1999 